\title{
Incidence of neurosurgical pathology of the spine in population of Mexico City
}

\author{
Incidencia de enfermedad neuroquirúrgica de columna vertebral en una población de la \\ Ciudad de México
}

\author{
Jahir Rodriguez-Morales ${ }^{1}$, Alejandro Méndez-Viveros ${ }^{1}$, Chelsy Pineda-Hernández², \\ Gustavo Parra-Romero', Erick Ariñez-Barahona', Sebastián Guartazaca-Guerrero', and \\ Lucía A. Méndez-García ${ }^{3 *}$ \\ ${ }^{1}$ Neurology and Neurosurgery Unit, General Hospital of Mexico "Dr. Eduardo Liceaga", Mexico City; ${ }^{2}$ Physiotherapy Unit, Universidad del Valle de \\ México, Campus Texcoco, Texcoco, State of Mexico; ' 2 Laboratory for Proteomics and Metabolomics, Research Division, General Hospital of Mexico \\ "Dr. Eduardo Liceaga," Mexico City. Mexico
}

\begin{abstract}
Background: Spine pathologies have been increased in the past years worldwide being important cause of disability which represents significant economic losses. Objective: The objective of the study was to establish the incidence of spinal neurosurgical pathology in a national reference hospital in Mexico City (General Hospital of Mexico "Dr. Eduardo Liceaga"). Materials and methods: A descriptive, observational, retrospective, and cross-sectional study was carried out, using the database of all patients that were undergoing spinal surgery from January 2015 to January 2020. Measures of central tendency and percentages, demographic variables, diagnosis, and affected segment were assessed. Results: $A$ total of 341 cases were analyzed, the group of patients with degenerative disease represents the main cause of care followed by neoplasms; trauma and special cases of congenital type and reoperations were the less frequent pathologies between the groups. In general, the most affected age group was 51-60 years. Conclusions: Within the study population, a wide range of diseases that affect the spine were treated, ranging from degenerative diseases, neoplasms, trauma, congenital, and infectious diseases.
\end{abstract}

Key words: Neurosurgical pathology. Spine. Degenerative spine disease. Spinal tumors. Spine fractures.

\section{Resumen}

Antecedentes: La incidencia de enfermedades de la columna ha ido en incremento en los últimos años a nivel mundial, las cuales representan una importante causa de incapacidad laboral e importantes pérdidas económicas. Objetivo: Establecer la incidencia de enfermedades neuroquirúrgicas de la columna en un hospital nacional de referencia de la Ciudad de México (Hospital General de México "Dr. Eduardo Liceaga"). Materiales y Métodos: Se llevó a cabo un estudio descriptivo, observacional, retrospectivo y transversal utilizando la base de datos de los pacientes que se sometieron a una cirugía de columna de enero del 2015 a enero del 2020. Se evaluaron medidas de tendencia central y porcentajes, variables demográficas, diagnóstico y segmento afectado. Resultados: Se analizaron un total de 341 casos, la enfermedad degenerativa representa la principal causa de atención seguida de las neoplasias y los traumatismos; los casos especiales de tipo congénito y las rein-

\section{Correspondence:}

*Lucía A. Méndez-García

Dr. Balmis, 148

Doctores, Cuauhtémoc

Date of reception: 02-10-2020

C.P.06720, Ciudad de México, México

Date of acceptance: 26-01-2021

E-mail: angelica.mendez.86@ hotmail.com

DOI: $10.24875 / C I R U .20001072$

Cir Cir. 2021;89(6):806-810

Contents available at PubMed

www.cirugiaycirujanos.com

0009-7411/@ 2021 Academia Mexicana de Cirugía. Published by Permanyer. This is an open access article under the terms of the CC BY-NC-ND license (http://creativecommons.org/licenses/by-nc-nd/4.0/). 
tervenciones fueron las patologías menos frecuentes. El grupo de edad más afectado fue de entre 51 a 60 años. Conclusiones: Dentro de la población de estudio se trataron una amplia gama de enfermedades que afectan a la columna, que van desde enfermedades degenerativas, neoplasias, traumatismos, enfermedades congénitas e infecciosas.

Palabras clave: Patología neuroquirúrgica. Columna vertebral. Enfermedad degenerativa de la columna. Tumores de columna. Fracturas de columna.

\section{Introduction}

Spinal column pathologies have become relevant worldwide because it has been reported an increment in the number of patients with degenerative spine diseases (DSD), tumors and spinal cord injuries secondary to trauma, with high rates of morbidity and mortality ${ }^{1,2}$. Most of the patients are young adults who are occupationally active. This represents a broad area of study, not only due to a large number of illnesses involved but also for the consequent disability that affects the productive population and which is reflected in large economic losses for society ${ }^{3,4}$.

Recently, international efforts have been done to establish the main causes of injury, being the degenerative disease the first place between the spine pathologies in the world ${ }^{5}$, for this reason, lines of research have emerged trying to establish management guidelines to implement effective treatments and improve the functional prognosis of patients ${ }^{6-8}$.

The traumatic spinal cord injuries have devastating physical, psychosocial, and vocational consequences for patients and health caregivers. Direct lifetime costs can reach up to $\$ 1$ 1.1-4.6 million US dollars per patient, with more than 1 million people affected only in North America ${ }^{4,9}$. An important problem is that most of the published literature corresponds to international studies with a population of phenotypic and demographic characteristics that are completely different from the Mexican population, for this reason is essential to generate evidence that supports the current state of our population, and even more to demonstrate the efficacy of established treatments.

The objective of this study is to establish the incidence of spinal column pathologies in a reference institution nationwide in Mexico City, and it is also an opportunity to start lines of investigation in the management of this type of pathologies.

\section{Materials and methods}

An observational, descriptive, retrospective, and cross-sectional study was carried out of all the patients who received medical attention and surgical management in the column clinic of the Neurosurgery service of our institution from January 2015 to January 2020. All patients accepted for admission to the service, regardless of gender or age, who received medical attention for pathologies in the spine and who underwent any neurosurgical procedure were considered in this study. With the information obtained, a database was created considering the following parameters: date, name, gender, age, diagnosis, type of surgery, type of injury, and segment of the spine affected. Once the database was completed, the study population was divided into four groups according to their diagnosis: patients with a degenerative disease, neoplasms, trauma, and others.

The sample size was calculated through the analysis of a proportion where the confidence level was $95 \%$, a coefficient $Z \alpha=1.96$, an expected proportion (p) of $50 \%$, and an accuracy (d) $3 \%$ resulting in a sample size of 203 cases. Statistical and arithmetic calculations, as well as the design of the graphs, were performed using the GraphPad Prism 7.00 program.

\section{Results}

The total number of patients admitted to the service during the period from January 2015 to January 2020 was 341 . As shown in figure 1 , approximately half of the total population were women with a total of $177 \mathrm{pa}$ tients at average age of $54 \pm 14.46$ years, while the masculine gender added 164 patients with an average age of $49 \pm 16.05$ years. In the study population, 80 of the patients were in an age range of 51-60 years, followed by 76 patients in a range of $41-50$ years (Fig. 2).

The main cause of injury was the degenerative disease with a total of 240 patients, followed by 66 patients treated for neoplasms, 26 patients were admitted for trauma and the rest are represented by other congenital injuries and readmissions with a total of 9 patients (Fig. 3). 


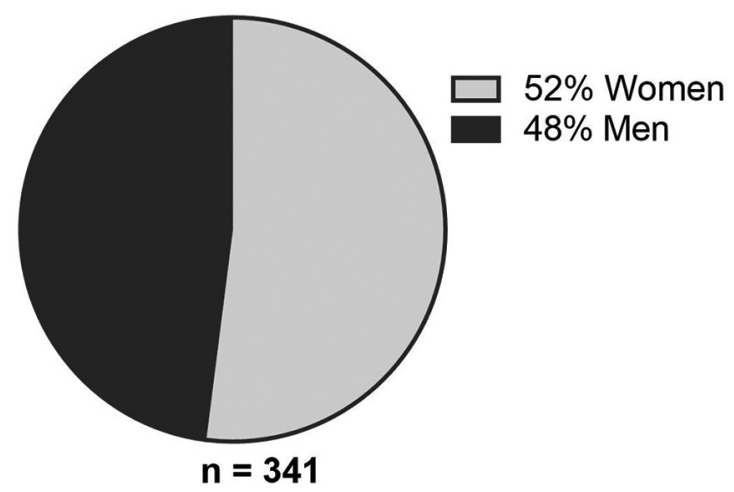

Figure 1. Gender distribution of the study population. $52 \%$ of the population is represented by women and the remaining $48 \%$ by men.

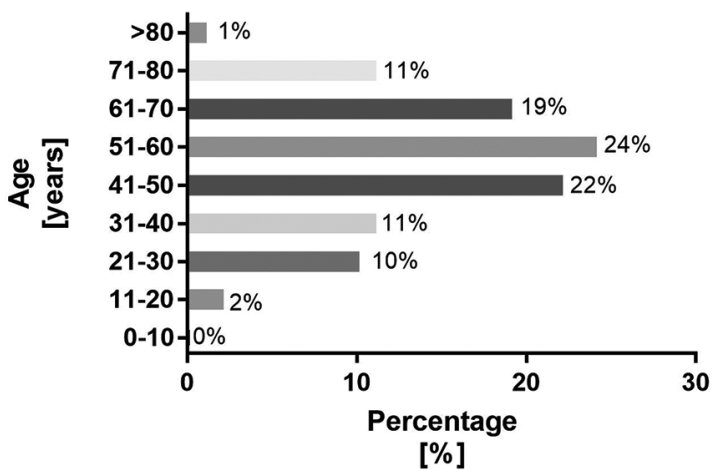

Figure 2. Spinal surgeries stratified by age. The most frequent age range $(24 \%)$ within the study population was 51-60 years, followed by the range of 41-50 years, which represents an important percentage of the population on productive age.

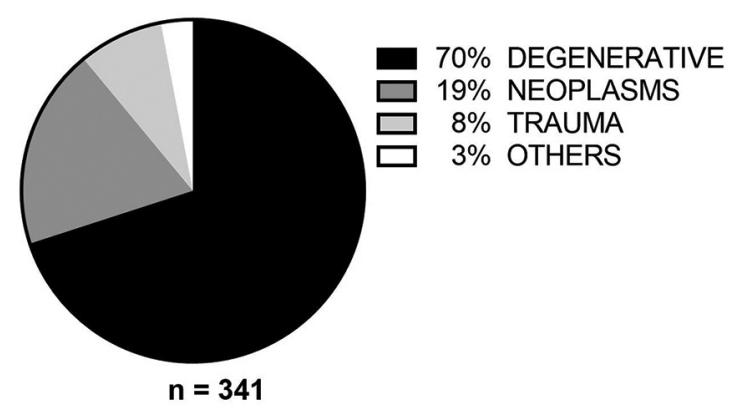

Figure 3. Causes of spinal surgery in the central Mexican population. The degenerative disease represents a large proportion of the pathologies in the study population, followed by neoplasms and, to a lesser extent, by trauma injuries and other conditions that include the congenital type, reoperations, and infections.

Figure 4A shows that lumbar hernias were the most frequent pathology within degenerative disease with a total of 79 patients, followed by lumbar stenosis with
69 cases and the cervical stenosis with 63 patients. Less frequent was patients admitted for degenerative spondylolisthesis, thoracic stenosis, and cervical hernias as well as thoracic hernia and facet syndrome. The rest of the patients were admitted for other injuries such as Tarlov's cyst and atlantoaxial subluxation.

Of the 64 patients who were admitted for neoplasms (Fig. 4B), meningiomas were the most frequent type of tumor with 16 patients, followed by 11 patients operated for ependymomas, Schwannoma, and patients admitted for lymphomas and metastasis. Four patients underwent surgery for neurofibroma, and three patients were admitted for hemangioblastoma. Less frequent was the admissions for astrocytoma, ependymoastrocytoma, granuloma, medulloblastoma, and lipoma.

Figure $4 \mathrm{C}$ shows that vertebral fracture was the most frequent type of trauma injury with 11 of the 26 operated patients, followed by spinal contusion, firearm injury, and less frequent injuries as spinal cord syndrome, brachial plexus avulsion, traumatic spondylolisthesis, and epidural hematoma.

Congenital lesions were represented for Chiari Malformation with three of the nine patients within the category of others (congenital lesions and readmissions and reoperations), in addition to anchored medulla, Pott's disease, abscess epidural, and cerebrospinal fluid post-surgery fistula. Finally, readmissions due to fatigue of the fixation material were also reported (Fig. 4D).

\section{Discussion}

The scant access to basic surgical care in Low- and Middle-Income Countries (LMIC) is the main limitation in epidemiological studies related with DSD, for this reason the epidemiology of this type of diseases is based on studies done in High Income Countries (HIC) such as Denmark, Hungary, United Kingdom, USA, and Canada, meanwhile LMIC has lower access to diagnostic, treatment, and epidemiological studies. However, estimations about the number of people affected by DSD in the world have been done, it is calculated that the annual worldwide cases of DSD and low back pain is 266 million people approximately ${ }^{1}$. Ravindra and coworkers (2018) proposed the incidence of DSD per 100,000 inhabitants based in only eight articles which they found optimal for the analysis. The higher incidence in European countries (5668/100,000 inhabitants) followed by countries of North America 
A

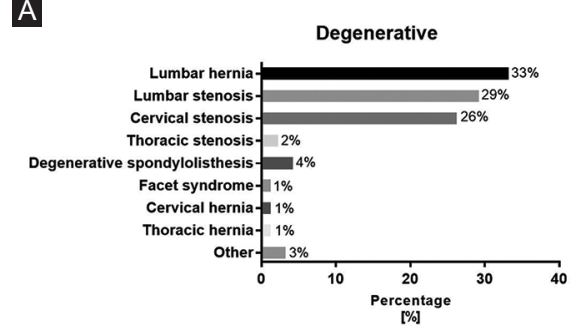

C

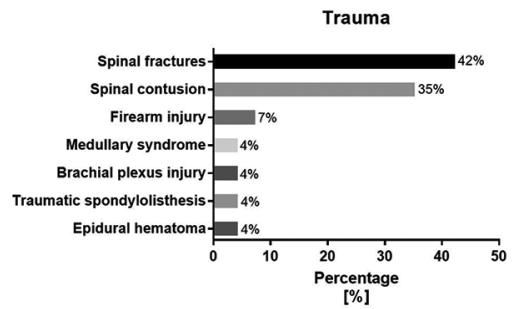

B
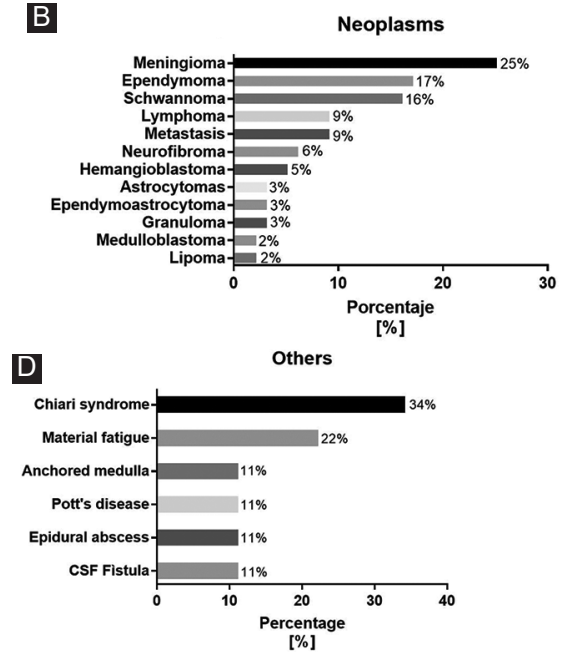

Figure 4. Groups of spinal pathologies in the central Mexican population. A: the degenerative disease was the most frequent pathology within the study population and within this group, lumbar hernias represented $33 \%$ of the cases followed by the lumbar stenosis and cervical stenosis (29 and 26\% respectively). B: neoplasms represented the most frequent pathology in the study population, meningiomas were the most frequent type of tumor (25\%) and ependymomas and Schwannoma were the second and third in frequency (17\% and 16\%, respectively). C: among trauma injuries, vertebral fractures were the most frequent pathology with $42 \%$ and spinal contusions the second position with $35 \%$. D: in the category of others, Chiari Malformation was the most common type of congenital pathology (34\%), followed by reoperations for fixation material fatigue with $22 \%$.

(4501/100,000 inhabitants), meanwhile countries of Latin America (3230/100,0000 inhabitants), Eastern Mediterrean Region (3014/100,000 inhabitants) and African countries (2420/100,000 inhabitants) represents the lowest incidence of DSD. Interestingly, the same trend was showed for the incidence of disc degeneration in the world ${ }^{1}$. However, as mentioned earlier, these estimations could be limited by many variables: first, the use of information to make comparisons of heterogeneous populations with different genetic background and lifestyles; second, the insufficient information in LMIC can lead to an underestimation in the number of people with DSD, and last but not least, most of the studies concerning DSD have been carried out in elderly people which excludes a significant part of the population at risk who are in the working age.

Although our study includes only 341 patients in a 5 -year period it is noteworthy that the most frequent spine pathology is by far the degenerative disease in this Mexican population, and between the degenerative disease, the herniated disc represents the pathology with highest incidence. It has been established that herniated discs are the most common cause of spinal surgery in the working-age population, genetic component, heavy lifting, and obesity have been identified as the main risk factors ${ }^{10}$. In Mexican population, PolancoArmenta and coworkers highlight the stenosis lumbar as the main DSD contrary with the findings of our study $^{2}$. These differences may be due to antropometrical and demographical characteristics of our population. In this study, the average age of patients who presented herniated disc was $45.5 \pm 14.6$ years, which represents the range of the population of working age in Mexico ${ }^{11}$. The most affected lumbar level between the groups was L4-L5, and the main occupations of the patients intervened for herniated disc were employees and domestic workers (data not shown). Interesting, our study population presented a body mass index (BMI) of $26.92 \pm 2.05$ within the overweight range. A seminal study showed that people at young age (25 and within 40-45 years old) and persistent overweight (BMl $\geq 25 \mathrm{~kg} / \mathrm{m}^{2}$ ) have high risk of disc degeneration mainly in the segment L4-L5 ${ }^{12}$, these anthropometric characteristics could explain the increased incidence of herniated disc surgery in this study compared with other published data in the same population ${ }^{2}$ since in this study approximately $78 \%$ of the population was within the overweight range (data not shown) and $45 \%$ of the patients were under 50 years of age. However, more studies are needed in order to have an integrative overview of the incidence and prevalence of DSD in the Mexican population and establish the genetic background and/or occupational component of this group that could be associated with the significant number of people with herniated disc. 
Otherwise, neoplasms represent the second place of incidence in our study population, meningiomas were the most frequent tumor. The previous reports support that meningiomas are the most common type of neoplasm of the spine in adults in the world. Female hormones have been reported to represent a risk factor in the development of meningiomas, every five individuals who present them, four are women, and one is a $\operatorname{man}^{13}$. However, the percentage of women affected in this study is $56 \%$, while men represent $44 \%$ of people who underwent surgery for spinal meningiomas, which confers a ratio of 1:1 approximately. Therefore, together with the hormonal factor, more risk elements associated with the development of meningiomas in our population must to be considered.

Finally, trauma injuries were less frequent cause of surgical intervention in our study population, mainly spinal fractures, and within this group, $64 \%$ presented fractures in the thoracic segment and the remaining $36 \%$ in the cervical segment. The epidemiology of this type of injury is currently scant. However, it has been determined that the main causes of spinal fractures are due to car and pedestrian accidents, and it has recently been established that both incidence and the rates associated with complications are increasing in the past years ${ }^{14}$.

The data obtained show the degenerative disease as the main neurosurgical pathology of our population and within this group, herniated discs are the most frequent cause of interventions. Diseases related to the spine represent an important cause of incapacity for work in the world. It is important to know both the prevalence and incidence of this type of diseases because this information is useful for the designing of prevention schemes, treatments and novel therapies that reduce both the number of people affected and the economic losses associated with it.

\section{Conclusions}

As a national reference hospital, we found a significant population where most diseases affecting the spine are resolved, ranging from degenerative diseases, neoplasms, traumatic, congenital, infectious, and specific injuries. The most frequent pathology that affects our population was the degenerative. Knowing the current epidemiological overview of these diseases allows us to identify the main effects in each of the aforementioned areas, laying the foundations for conducting research studies focused on the determination of risk factors, prevention schemes, and treatments.

\section{Acknowledgments}

The authors thank whole work team of the Neurosurgery service and the Research Division of the General Hospital of Mexico that made this work possible.

\section{Conflicts of interest}

The authors declare that does not exist an conflict of interest.

\section{Ethical disclosures}

Protection of human and animal subjects. The authors declare that no experiments were performed on humans or animals for this study.

Confidentiality of data. The authors declare that they have followed the protocols of their work center on the publication of patient data.

Right to privacy and informed consent. The authors declare that no patient data appear in this article.

\section{References}

1. Ravindra VM, Senglaub SS, Rattani A, Dewan MC, Härtl R, Bisson E, et al. Degenerative lumbar spine disease: estimating global incidence and worldwide volume. Glob Spine J. 2018;8:784-94.

2. Armenta AG, Martínez EE, Gonzalez RT, Garfias AR, Prado MG. Epidemiological panorama of orthopedic spine pathology in Mexico. Coluna Columna. 2018;17:120-3.

3. Cahueque-Lemus MA, Cobar-Bustamante AE, Bregni-Duraés MC, Jiménez-Ávila JM. Síndrome de destrucción vertebral: del entendimiento a la práctica. Acta Ortop Mex. 2018;32:182-7.

4. Ahuja CS, Nori S, Tetreault L, Wilson J, Kwon B, Harrop J, et al. Traumatic spinal cord injury-repair and regeneration. Clin Neurosurg. 2017;80:S22-90

5. Wang YX, Káplár Z, Deng M, Leung JC. Lumbar degenerative spondylolisthesis epidemiology: a systematic review with a focus on gender-specific and age-specific prevalence. J Orthop Transl. 2017;11:39-52.

6. Jiménez-Ávila JM, Sánchez-García O, González-Cisneros AC. Guidelines in the decision of surgical management in spine surgery. Cir Cir. 2019;87:299-307.

7. Jiang G, Ye C, Luo J, Chen W. Which is the optimum surgical strategy for spondylolisthesis: reduction or fusion in situ? A meta-analysis from 12 comparative studies. Int J Surg. 2017;42:128-37.

8. Pannell WC, Savin DD, Scott TP, Wang JC, Daubs MD. Trends in the surgical treatment of lumbar spine disease in the United States. Spine J. 2015;15:1719-27.

9. Vaccaro AR, Schroeder GD, Kepler CK, Oner FC, Vialle LR, Kandziora $F$, et al. The surgical algorithm for the AOSpine thoracolumbar spine injury classification system. Eur Spine J. 2016;25:1087-94.

10. Schroeder GD, Guyre CA, Vaccaro AR. The epidemiology and pathophysiology of lumbar disc herniations. Semin Spine Surg. 2016;28:2-7.

11. Gonzalez KD. Envejecimiento Demográfico en México : análisis Comparativo Entre las Entidades Federativas. Conapo; 2015. Available from: http://www. conapo.gob.mx/es/CONAPO/Envejecimiento_demografico_en_Mexico.

12. Liuke $M$, Solovieva S, Lamminen A, Luoma K, Leino-Arjas $P$, Luukkonen $\mathrm{R}$, et al. Disc degeneration of the lumbar spine in relation to overweight. Int J Obesity. 2005;29:903-8.

13. Ravindra VM, Schmidt MH. Management of spinal meningiomas spinal meningioma atypical myelopathy intraoperative monitoring. Neurosurg Clin N Am. 2016;27:195-205.

14. Passias PG, Poorman GW, Segreto FA, Jalai CM, Horn SR, Bortz CA et al. Traumatic fractures of the cervical spine: analysis of changes in incidence, cause, concurrent injuries, and complications among 488,262 patients from 2005 to 2013. World Neurosurg. 2018;110:e427-37. 